of potash or soda. Iron must be given with cantion, and omitted if the patient is full-blooded, over-fed, or constipated ; anzmia is, of course, an indication for it.

The normal termination of the granular kidney is by aræmia, though there are many pitfalls by the way. In order to obvate this tendency to a fatal issue sweating should be enforced where the tendency is declared by headache, vomiting, or otherwise. A Turkish bath at regular intervals, every ten days or a fortnight, may long ward off what would otherwise happen. When from the distance of the bath or the state of the patient this is not available the lamp bath should be used at home; and I may speak especially of a modification of it which for some years past II have been in the habit of employing. When a patient is in imortal peril one may hesitate to enforce so powerful a measure as the enclosure of the whole body in hot air; his hold of life may be feeble, and there may be a fear of disturbing it: but if the heated air is applied only to the feet or below the knees much good may be done, and, so far as I have seen, never any harm. One wicker arch only is used instea of several ; the hot air thus limited will make the Aower extremities perspire freely, while the whole body will do so to a less degree. I have found this partial bath-" the "leg bath, " as I call it-to be invaluable. If this procedure - does not cause the patient to perspire, as is sometimes the sase, pilocarpine may be injected subcutaneously before the bath is applied. Another preliminary measure which is useful such cases is to place the patient for two or three minutes in a bath of very hot water, say, at $110^{\circ} \mathrm{F}$., before the hot-air bath-which in such a case would, of course, involve the whole body-is applied.

As dropsy is one of the most prominent symptoms of albuminuria $T$ will say a word or two about its treatment. Nature's cure for renal dropsy is hypertrophy of the heart. ${ }^{3}$ This may be presumed to act by way of the veins; the increased suction power of the thickened left ventricle must draw apon these channels and so pump out the water-logged tissues, while the hypertrophy of the right ventricle, slight but real, must likewise help on the venous circulation. Renal dropsy, therefore, tends to recovery, but the process is slow and needs to be expedited. AEdema of the legs, whether renal or cardiac, is relieved by posture-not merely moved, but removed. Beyond this, measures of two kinds tend to benefit renal dropsy-those which lessen the contents of the vessels, and those which increase the force of the heart, Digitalis, I think, is almost invariably indicated; it probably acts upon the heart and ressels in the first place, and upon the secretion of the kidneys only secondarily. do not think that the way this drug acts in renal dropsy is entirely clear; it is known to increase the contractile force of the left ventricle, but does it increase its expansile force? It is not known that it does so. No doubt the increase in the contractile force of the right ventricle must tend to relieve dropsy, but beyond that one does not see very clearly. However, whatever obscurity there may be about the modus operandi there is no uncertainty as to the beneficial result. Most reputed diuretics are useless and some, like cantharides, are injurious. I have learned to distrust and avoid the whole class, with the reservation of digitalis and the vegetable salts of potash, which, in addition to their other properties, are slightly diuretic. Hydragogue purgatives and hotair baths have their use, and, I may say also, their abuse. Depletion may be carried too far and a condition of anæmia maintained by which dropsy is promoted rather than relieved. Exbausting measures ought, therefore, to be used with moderation and counterbalanced, according to circumstances, by food and iron. Among the purgatives which are useful in such cases the mercurials are not to be rigidly excluded, though they ought to be given seldom and in small doses. In considering the benefit to be derived from purgation and diaphoresis in renal dropsy it is not to be forgotten that the initial causes of this form of the disease are probably the contamination of the blood and its altered relation to the capillaries, and the circumstance that evacuation tends to carry of the peccant materials. The abdomen may be tapped with safety, by which means not only it, but the legs will be relieved; punctures of the legs by any process, whether with tubes or needles, should be avoided as being full of danger, however apparently trivial the operation.

Renal asthma, distressing and alarming as it is, admits of relief, and even of cure, by treating the uræmia in which it

3 See paper on Renal Dropsy in the Medical and Chirurgical Trans actions for 1892 , rel, Ix Dr. takes its rise. Ethers, alcohol, and nitrite of amyl are of temporary use; but the mainstay is in the evacuants, hot air baths, calomel, and the hydragogues. The pulse under these attacks often shows extreme over-tension, on lessening which they will abate or cease to recur.

With regard to the over-tension of the advanced granular kidney a caution may not be out of place. We should not attempt to lower the pulse-tension to an ideal of health, as the result would probably be death; the circulation is carried on under difficulties and only by means of increased force. The hypertrophy of the heart is a measure of salvation and the increased tension is a necessary condition. We should consent to a moderate increase of tension and seek to modify it only when it is excessive.

Mental disturbance is rare, but not unknown, in connexion with the advanced granular kidney. Depression or melancholy may long precede death. More immediately foretelling the fatal issue are the lesser degrees of wandering or delirium and what I suppose may be called "chronic mania," insanity with delusions. I have learned to regard the latter conditions as of evil omen.

To bring to an end these trivialities of practice I will say a word or two as to the treatment of the lardaceous disease and the relation of the alkalies to the morbid deposit. There is much to suggest potash as remedial. Apart from syphilis, the only ascertained cause for the disorder is suppuration, a process which necessarily entails a loss of potash. The relation of the discharge to the deposit is so direct as to suggest some such arithmetic as this: take pus from blood, and the lardaceous matter remains. This matter is distinguished from the normal constituents of the body by its deficiency in potash and by its ready solubility in alkalies. The suggestion cannot fail to present itself that the substance is deposited in consequence of a deficiency in the blood of the normal alkaline solvent; but there are in the living body complications which the test-tube cannot reveal, and therapeutics based only on chemistry are apt to miss their mark. The loss of pus which causes the lardaceous deposition is not only a loss of potash but of the white corpuscles in which it is contained; the loss of the organisms cannot be ignored, nor can potash by itself replace them. Then, again, it has to be considered that, however readily the lardaceous material can be eliminated from an organ by liquor potassæ after death, it is not quite so easy to get that reagent to bear upon the tissue during life. 'The material is dissolved only by the caustic alkalies, not by their salts, and the action of the blood upon these alkalies has to be considered. Nevertheless, I think it is wise, and I am sure it is harmless, to give a little liquor potassæ upon an empty stomach when suppuration is present ; but general restorative treatment is what ought to be mainly relied upon--viz., a liberal diet and sea air, with iron and quinine and cod-liver oil. I have seen more good result from a sojourn at Margate than at any other place. When the lardaceous condition is due to syphilis the benefit produced by the long-continued use of iodide of potassium, possibly conjoined with iodide of iron, is remarkable. In order to obtain the greatest good from such medicines they should be given for years; I often propose two years as the duration of the course and have many times continued it for longer than this with advantage.

\section{THE ETIOLOGY OF CHRONIC HERNIA, WITH SPECTAL REFERENCE TO THE OPERATION FOR RADICAL CURE.}

BY E. STANMORE BISHOP, F.R.C.S. ENG., HON. SURGEON, ANCOATS HOSPITAL.

THAT the operation for the radical cure of hernia is not in an ideal position will, I suppose, be admitted by all surgeons ; the great majority of the profession do not look upon it with favour, being extremely doubtful of its permanent success, and their opinion is focussed in the statements of many of the leading authorities. Thus, Dr. William White of Pennsylvania commenting on Richelot's results, says: "' "'he general experience of surgeons everywhere is that at least from 40 to 50 per cent. of cases operated upon for the radical cure suffer from relapses." I Dr. Wyeth says: "I am averse to the operation for radical cure, except where strangulation has 
occurred or the intestine has become incarcerated, or the ,hernia has become so large that it interferes with the usefulness of the individual. I have never advised an operation except in such conditions, and never will until I see better results in efforts at radical cure." 2 Dr. Bull, in summing up a paper of his on the results of operations for this purpose, says: "The figures I bring forward are in evidence of the inefficiency of all operations for radical cure." 3 English surgeons hold much the same opinion. Birkett, in "Holmes' System of Surgery," in an article entitled "On the So-called Radical Cure," quotes with approval the words of Lawrence: "The operation affords no greater prospect of entire recovery than he [the patient] bad without it, for after he has undergone an operation at the hazard of life the complaint may return, and the only protection against relapse is to wear a truss." Erichsen says in his "System of Surgery" 5 that "the only plan that is at the same time perfectly safe and -permanently successful is the compression of a well-made truss." Dr. Mitchell Banks ${ }^{6}$ considers that the term "a radical cure" is a misleading one, and the main reason is that "a man who gets a rupture has naturally a weak and yielding canal or ring, and when you have patched him you can only put him in the same position he was in before the rupture, because he will still be a man with a weak condition of his abdominal wall." Such pronouncements might be multiplied almost indefinitely, but it is needless to do so. Generally, it may be said, despite the personal enthusiasm of certain operators, that the great majority of the profession look upon the idea of a radical cure of bernia as something which may now and then happen, with great good fortune, but as certainly not a thing to be depended upon. There must be a reason for this state of things, and the surgeon of to-day can hardly be expected to accept such a position as final. So many things which were formerly looked upon as hopeless have been found to be practicable under new conditions and with new technique that we cannot but be hopeful that this difficulty, too, will be found soluble. Under similar circumstances, by going carefully over the factors which go to make up our conception of the condition requiring remedy some error has occasionally been detected in the primary ideas, some fault in the line of reasoning, or, finally, some trivial mistake in the technique, the discovery and correction of which have been followed by success ; and the present communication is intended as an attempt towards so desirable a result. Practically in what is to follow congenital hernia will be excluded : first, because proper attention to the use of well-fitting trusses in early life will render any consideration of operative measures in the great majority of cases unnecessary ; and, secondly, because the great difficulty in operations for the radical cure of hernia is most intimately connected with acquired and not with congenital hernia. I am anxious also to be understood as dealing, not with rare or curious-often described as "interesting" -cases, but as discussing the cases met with every day, the great majority of common, ordinary hernix.

It will, perhaps, be well first to formulate what is generally taken for granted-viz., the prevailing ideas as to hernia; and the following, I believe, may be taken as postulates. (1) That hernia is a protrusion of viscera from their normal plane through the walls which ordinarily contain them; (2) that viscera which are normal, contained within walls of normal strength, do not protrude; (3) that if viscera protrude such a condition is due to (a) an inordinate length of their attachments (the mesentery), (b) an abnormal attachment of the mesentery to the back of the abdomen (Mr. Lockwood), (c) constitutional weakness of the walls and abnormal patulousness of the normal orifices (Dr. Mitchell Banks), and (d) effects of injuries, operations, sudden strains in lifting, \&c.; (4) that reducible, incarcerated, obstructed, and strangulated herniæ are all varieties of the same condition; and (5) that the results of operation for radical cure upon all varieties should influence our prognosis as to the prospects of any one (this, when baldly stated, will probably not be admitted, but it is practically acted upon), Of these postulates I would draw more particular attention to the fourthviz., that reducible, incarcerated, irreducible, obstructed and strangulated hernix are all varieties of the same condition, varying only in the pathological appearances, the acuteness of their symptoms, and the urgency with which they re-

International Journal of the Medical Sciences, 1892, vol. liv., p. 350 ${ }^{3}$ New York Medical Tournal, 1891, vol. liii., p. 630 . 4 Third edition, vol. ii., p. 763 . 5 Seventh edition. vol. xi. p. 618 .

6 Brit. Med. Jour., 1887, vol. iv., p. 1261. quire surgical intervention. Is this true? Leaving congenita] hernia out of the question I suggest that all other cases off hernia are naturally divisible into two distinct classes, which have little or nothing in common-acute or strangulated anci chronic or reducible hernive, and that these are distinct in causation, pathology, and course, and that their treatment. and the results of their treatment should also be considerect apart. Under chronic hernix I would include incarceratec and obstructed herniæ, as these terms merely emphasise certain incidents or modifications in the life history of chronic hernia.

Causation of hernia.-The distinct exciting causes of acute hernia are doubtless those usually given-viz., strains, sudden exertions, such as lifting \&c.; but these can never, as I hop\&to show later, produce a chronic hernia, the actual efficien causes of which have certain peculiarities. They are compara. tively gentle, they act continuously or frequently, with short intervals, and from within ; they are more or less habituat; so that they are often lost sight of, and they are nsually, removable or preventable. One might say that the causes of acute hernia act rapidly, forcibly, desperately; those of chronic hernia slowly, gently, and with malice aforethought, In legal language the one is " manslaughter," the other "murder." The one is unavoidable but happens seldom, the other curable or avoidable, but happens frequently. The curability or avoidability of the cause is important, inasmuch as it follows naturally that the results of a cause which bas ceased to act can with much more certainty be remored than those of a force which is still in operation.

Pathological appearances. - The pathological appearances will be referred to again. They may here be simply men... tioned. The peritoneal sac in chronic hernia is slowly pro. duced and is never tightly distended; it lies in folds at the point of exit from the abdomen. These folds ridiate outwards. and upwards over the parietes and tend to unite when once the efficient cause is removed, so as to form a collar at the level of the rings. The sac usually becomes thicker as time goes on, being sometimes ossified or otherwise changed, but always in the direction of hypertrophy. In aeute hernia it is thin, tightly distended, and possesses no folds.

Course of the malady.-Chronic hernia is essentially a very slow process from beginning to end. It has three stages: (1) a stage which may be described as "prehernial" or that which is passed through before any external appearance is discovered ; it is peculiar to this form of hernia, it cannot exist in the congenital form, for reasons which will be obvious, and it does not exist in the strangulated variety, unless this supervenes as an acute attack in the course of a chronic one: (2) the stage of growth, which lasts from the time of appearance to the period when the efficient cause ceases to act; and (3) the stage of rest, when the efficient cause is removed, and only subordinate or accessory causes remain in operation. In acute hernia there is but one stage terminated by operation, unless reprehensible delay is permitted, when there are two-the stage of tension and the stage of gangrene. The results of treatment should be kept distinct. In acutehernia the state of the bowel is of the first importance; in chronic hernia the state of the abdominal wall. In acnte hernia operation is a matter of immediate necessity; in chronic hernia it is one of convenience. In acate hernia the risk to life is great ; in chronic hernia it is almost nil. In acute hernia the vitality is already, before surgical inter. ference, greatly lowered, generally to such a point that the expenditure of a few minutes more or less over an operation: may make all the difference between life and death to the patient. In chronic hernia the time erpended on the operation is of very secondary importance, so that every detail as to technique may be carefully attended to. An operation, therefore, on acute hernia must be carried ont under the very worst conditions for obtaining a permanent result: whilst in chronic hernia the efficient cause may first bo removed, leaving only its results to be dealt with, the most favourable period as regards the patient's health and surounding conditions may be chosen, and the operation may be carefully carried out with the perfect attention to detail which is necessary to secure permanency in the results, without the dread of vital exhaustion inseparable from operations on acute hernia; and this is the more important from the standpoint of permanent results, inasmuch as the foundation of a relapse is often laid during the first week after operation whilst the parts are still in a plastic condition, when, should the efficient cause be still acting, bulging of the soft, uniting tissue is unavoidable. If the viscera protrude such a condition is due to: (1) the inordinate length of the mesentery: 
(2) the abnormal attachment of the mesentery to the spine, or, as Mr. Lockwood calls it, "prolapse of the mesentery" 7 (these may be admitted, but they only refer to unusual cases, cases decidedly in the minority, and do not at all explain the great majority. Compare the statement in Mr. Lockwood's Hunterian Lectures - " the youngest subject in whom I have found this condition was thirty-one years of age, and the next youngest was forty nine "-with the Truss Society's table, in which it is clearly shown that 75.44 per cent. of the whole number of herniæ occur before forty years of age, and 6779 per cent. before thirty-five years of age; and also with reference to the first a further statement by the same authority ${ }^{8}$ " The length of the mesentery has been measured in twenty-one people with acquired sacs or hernix, and whose ages ranged from thirty-one to eighty-five years. In none of them did the mesentery exceed the length which is ordinarily met with in people of their time of life. It is noteworthy that in as many as nine the mesentery should be below the average length of $7 \frac{1}{2}$ in." It is evident, therefore, that, making every allowance for the possibility of the occurrence of cases which admit of such explanations, the great majority of cases are untouched by them); (3) constitutional weakness of the walls and abnormal patency of the normal orifices; and (4) the effects of injuries, operations, sudden strains, as in lifting unusual weights, \&c. Are these last two correct? If they are absolutely correct the chances of success in attempting the radical cure of reducible hernia are but small, since we have but poor weak tissues to work upon, and no surgeon can guarantee his patient against the common accidents of life. Practical surgeons will therefore turn their attention, as they have generally done in the past, to more profitable and satisfactory work. If they are not correct, may not our preconceived ideas on these points have influenced our practice, as well as our prognosis? The effects of previous operations on the abdominal wall may be allowed to stand over, inasmuch as such results may be avoided by better technique, and in any case the number of hernix due to this cause is but small, and thus still the great bulk of reducible hernix remains unexplained. Are reducible, or, as I prefer to call them, chronic, herniæ ever due to a sudden strain or over-exertion? Is it the fact that the reason why such strains produce hernia in one man and have no effect on another is that the first is of poor, flabby, unhealthy physique, while the latter possesses normal tissues? Is this true? Because, if it is not, much of the present practice which is, consciously or not, founded upon sach preconceptions will be open to reconsideration and probably to modification. I believe that this conception is not the correct one, and for the following reasons. 1. A careful stady of pathological specimens of reducible hernia reveals none of the changes usually to be found in lesions of other parts of the body due to sudden causes. It reveals, rather, very definite and well-marked differences between herniæ which have been produced suddenly-i.e., strangulated or acute hernix-and those now under consideration. The appearances actually seen are such as are only compatible with the action of a comparatively gentle but persistent and prolonged continuous or frequently intermitting force. 2. A superficial inquiry into the history of a reducible hernia is as a rule glibly met by a declaration of some injury ; but more careful cross-examination will usually succeed in eliciting the existence of some condition antecedent to the injury credited with the mischief, a condition potent for evil, but usually overlooked or ignored by both patient and examiner. 3. Many persons suffering from hernia are men who have enjoyed continuous good health, are descended from healthy parents, are physically stronger than their fellows, and many have shown, by the fact that they have reached a ripe old age in spite of this drawback, that they are of good constitution.

Pathological specimens. - The abdomen, we know, is a closed chamber, whose walls are divisible for the purpose under consideration into three - the peritoneal, the muscular, and the cutaneous. The cutaneous may for practical purposes be ignored, since when once the other two have yielded it offers no serious resistance, and in the operation for radical cure it is of no moment, its yielding, distensible character rendering it useless. The contents of the abdomen fit it accurately, so that a diminution in its capacity means internal pressure upon its walls in every direction. Of the two coats, muscular and peri- toneal, both elastic, the muscular is far less dilatable that the peritoneal; the latter is complete, the former is not There exist in the former, the outer coat, certain portions not so firmly constructed as the remainder, but yet, under ordinary circumstances, quite equal to give the necessary suppori. When, however, the abdomen contracts, the increased tensin brought to bear upon that portion of the serous lining mew. brane which covers those weaker parts, causes it to bulge slightly. If the tension is now relaxed the natural elasticity of the wall restores the serous membrane to its original position. Should the tension be repeated quickly enough, so that the original effect has not quite disappeared, the elasticity is slightly diminished, and the return is not quite so perfect, but a slight pouching remains, while the peritoneum around the part thrust outwards is slightly dragged upon and dis placed towards it. Should this process be repeated steadily and for a sufficient length of time the inner wall becomes slowly pushed outwards, drawing with it more and more of the surrounding peritoneum to assist in forming a small cone, open inwards, projecting in the line of least resistance $^{9} \quad$ This is the first stage, usually ignored by the patient, but occasionally, as the following cases go to show, causing much discomfort, which is often apparently unexplainable until the later appearance of the hernia throws light apon it. At this time there is no external tumour, the process is too gradual to cause vomiling or constipation or any of the symptoms which mark acute hernia, and until this time there has been nothing sudden or unusual to fix the attention of a patient. The cause acts so gently and so readily becomes habitual that nothing is thought of it, and its potency for evil in this direction is ignored. The following cases illustrate this point, and similar ones may be found in sufficient number if looked for.

CASE 1. - The case, which was that of a woman thirty-nine years of age, was communicated to me by my friend Dr. Cluff of Openshaw. She was suffering from a right inguinal hernia. When she was about twenty-seven years of age she nursed her mother, who was paralysed, for two years. During this time she felt aching pain in the inguinal region radiating over the abdomen. Nothing, however, could be detected by Dr. Cluff, who examined her several times, to account for it. One day, after the pain had lasted for several weeks and had become established, whilst lifting a bucket of water, a comparatively light weight, she felt something "give way" at the seat of the pain and discovered the rupture.

CASE 2.-This case was that of an athlete. The herni: was a right inguinal one. He had not taken part in running or jumping for twelve months when he came under observation, because about that time he suffered from influenga and had a distressing, hard, dry cough, which lasted for a month He first noticed the hernia two months before he sought advice. He had no idea what caused it.

CASE 3. - This patient was a man seventy-four years of age. He had worked at a rubber factory formany y ears; he had of ten been "wet through," going and coming from work. During the winter he had suffered for many years from cough, it being so severe sometimes as to provoke vomiting; the cough was always hard, and little or no sputum was expectorated. He thought little about it, as many other men suffered from a cough, and it was always better in summer. While he was sitting smoking in his easy chair one night he coughed slightly and felt something give way. He found subsequently that he had a slight inguinal rupture. He had no idea what caused it.

In the report of the North of England Gynæoological Society for March, 1893, Dr. Rabagliati of Bradford reporte two cases of commencing umbilical hernia, in which the symptoms were similar to those in Dr. Clnff's case, and in which a small opening was found on operation. That the inner wall is dislodged from the outer around the advancing cone and helps to form it is well shown in specimens in the Museum of the Royal; College of Surgeons of England, Nos. 2609, 2612, and may indeed always be found more or less plainly in all specimens of chronic hernia. This slow dragging inwards of the parietal peritoneum is shown by the folds which have always been described as existing at the neck of the sac, but still more by what has not apparently attracted as much attention-viz, the fact that these folds radiate upwards and outwards over the interior of the abdominal wall for a very considerable distance. Specimens showing this are Nos. 2123, 2127, in St. Bartholomew's Hospital Musenm, 
and Nos. 2609, 2612, in the Museum of the Ruyal College of Surgeons of England. Has the fact been appreciated at its full value that :uch folds only exist in an acquired reducible hernia, that they are never seen in a congenital or an acute hernia-that, indeed, if by nothing else, a chronic hernia can always be recognised by their presence? Such a condition surely implies displacement-slight separation of the inner from the onter wall for a considerable extent of surface; such as, were it produced at once, would almost inevitably be associated with small hæmorrhages and with slight or greater tearing of the thin membrane, if not by consequent inflammation; but none of these results are ever seen. Surely, therefore, the condition must be produced by a gentle force acting continuously, or at frequent intervals, over a prolonged space of time. This is the first stage. The slowly forming and advancing cone has opened out the internal ring and is beginning to press like a wedge upon the tissues of the canal. It may even have opened out the canal itself for some distance before it is discovered. If now a sudden and more forcible contraction of the abdominal cavity than usual should take place, such is would be produced by sudden lifting, jumping, \&c., the wedge-like cone may be forced between the fibres, which separate with an appreciable sensation and the somewhat sudden recognition of the hernia from without. This, however, is only an incident in the course of such a hernia, upon which the efficient cause has already been at work for some time; is only possible, in fact, when the first stage is over, and is by no means always present. I have, indeed, been greatly struck by the numerous cases I have found of men with large hernix who had no idea as to how they became possessed of their unwelcome encumbrances. This is the commencement of the second stage. The efficient cause being still in action, the peritoneal wedge slowly dilates the tissues it has passed through and opens up those in front of it, proceeding always in the line of Jeast resistance, until it reaches such a point that its own weight begins to tell, and gravity reinforces the antecedent force; but whilst accessory, and in the later portion of this stage rather a powerful accessory to the enlargement of the sac, weight is certainly not the only factor, as a specimen, No. $2486^{\text {j2 }}$ in Guy's Hospital Museum, conclusively proves. The sac here has enlarged in two directions-one downwards in the usual line, and one forwards and inwards towards the pubis. Always what I have called the efficient force remains the dominant factor. Other specimens which go to prove the foregoing are in St. Bartholomew's Hospital Mruseum, No. 2083A, and the Museum of the Royal College of Surgeons of England, No. 2612.

It is also to be remembered that during this, the second, stage, the peritoneum, at first a thin, fine membrane, becomes slowly hypertrophied, so that it is in some cases a quarter of an inch thick or more. This surely points to a constantly recurring irritation, not sufficient to cause inflammation, but enough to induce growth. Specimens showing this are Nos. 2081, 2082A, 2111, 2124, St. Bartholomew's Hospital Museum; No. 2607, Museum of the Royal College of Surgeons of Holend and No. $2494^{30}$ Guy's Hospital Museum. Should the officient cause cease to act, a third stage is reached. Whe peritoneum now ceases to be protruded from the abdominal cavity and lies at rest in the passage it has formed. The folds in which the inner wall is disposed, lying quietly side by side, begin to unite, and over and between them a layer of lymph is thrown out, which forms a collar (St Bartholomew's Hospital Museum, Nos. 2123, 2124 ; Royal College of Surgeons Museum, No. 2608). They also become united to the tissues without. Should the cause again return this collar may be forced away from the point united, and the process starting afresh becomes the funclus of a secondary sac, formed in its turn by peritoneum dragged from the interior and stretched and lengthened in the process. The formation of the collar and these latter processes are well shown in one of Hunter's specimens in the museum of the Royal College of Surgeons, No. 2610. His description is worth repetition. "We dissected," he says, "a man who had rupture of a particular kind, a sort of double rupture on the same side and in the same passage and in the same sac. It appeared to me as if produced at two different times-that the man had a small inguinal rupture for some time, the contents epiplocn, and that the mouth of the sas had contracted a good deal, so that no return of the epiploon could be brought about. Whilst in this state a second or new cause took place and, instead of dilating the old sac by pusbing into it more epiploon, pushed down the old sac, ard a new elonga- tion of the peritoneum followed. This last was by far the largest." As I suggest, the cause, bronchitis or other, which was cured for a time-long enough for the requisite changes to take place in the neck of the sac-returned later in the patient's life and was the more persistent, partly, doubtless, because he was now, by so much, an older man. A similar case is mentioned by South. ${ }^{10}$ A specimens showing still further the way in which, by the enlargement of a hernial sac, the internal peritoneum is dragged upon, I would instance No. 2111 in the St. Bartholomew's Hospital Museum, showing the sigmoid flexure dis placed downwards until it rests immediately above the internal orifice of the sac, and No. 2111B, from the same collection, in which the cæcum bas in a similar manver been drawn to the edge of the neck of the sac. Is it not possible that Mr. Lockwood's prolapse of the mesentery, and the elongation of that membrane occasionally seen, may be produced in a similar manner? Such an examination of specimen of chronic hernia proves, I think, that it is impossible that the real efficient cause of chronic hernia can be a sudden onesuch as a strain, overlifting, jumping, and the like; and therefore that the usual history given is not the true one, but that more efficient and more easily overlooked canses must exist. My lists will, I think, show that these are usually to be found if carefully sought. They will also incidentally prove, I hope, my third proposition that the possession of a hernia is not a proof of poor constitution or relaxed muscular tissue. At first I hoped to have obtained information from various works and factories showing the proportionate numbers of men affected who were engaged in different employments, but I have been disappointed. The British working man, as we know him (at least in the North) is, with some honourable exceptions, extremely suspicious and distrustful. He sees or thinks he sees behind any attempt of this kind to obtain reliable statistics a mean attempt on the part of his master or the directors of the company employing him to eliminate the weaker members of the trade; and, partly, no doubt, owing to what I believe are the false ideas current respecting hernia, which are the reflection of our own teaching, he considers it a confession of weakness, or worse, to admit the possession of such an ailment. The lists from these sources are therefore useless, as the information they give is too frag. mentary ; but by the courtesy of the Prison Commissioners I have been able to examine the male prisoners in the gaols of Manchester, Preston, Liverpool and Knutsford. I have also been able to tabulate the male inmates of the Liverpool Workhouse. For the latter privilege I am indebted to Dr. Alexander and Dr. Haslett of Liverpool, who rendered me every assistance in their power. I am also indebted to Dr. Orchard of the Chorlton Workhouse for permission to examine patients in that institution. Examination of these cases brings out prominently certain very interesting facts, some of which may be pointed out.

1. A fair number (24 per cent.) gave the history of a strain or lifting a heavy weight without any hesitation at all, bot on closer questioning it came out that in some cases the strain to which they attributed all their trouble had taken place a considerable time before the date on which they first discovered a swelling. Thus, in one case three or four weeks and in another eight or nine months elapsed between the accident blamed and the appearance of the hernia, whilst a third who found the hernia in 1872 went as far back as 1869 for its cause, and a fourth gave as the cause a fall from a scaffold twelve years before the first appearance of rupture.

2. A certain number could give no reason whatever, their minds being directed always to some sudden accident as the only possible cause for their condition, but on cross-examination one or the other of the causes I suggest as the efficient ones were usually found to be present. One case was peculiarly instructive. This was a man sixty-six years of age, who was operated upon eight years previously. The patient said that the surgeon who operated upon him was partict. larly anxious to elicit the cause of the hernia before opera. tion, but the man could not trace it to anything. The rupture "came of itself," he said. The operation was done but there was a relapse in eighteen months. Could it be wondered at, when the man was evidently slowly dying from chronic bronchitis, from which he had snffered for more than forty years?

3. A certain number attributed the rupture at once to cough. "Sure, 'twas dint of heavy coughin'," said one Irishmal 
eventy-five years of age, but very few appeared to have any idea that their herniæ might be due to this.

4. Some accused the most unlikely things. One man in Strangeways Gaol believed it to be due to masturbation, another to the shock of having once drunk cola water, another to the pain of an injured hand \&c.

5. Whilst occurring in men of poor physique and owning feeble parents, it was by no means limited to such. Some of those with large herniæ were strong, stalwart men, or had evidently been so at the time when the hernix appeared, as the following three cases will show, whilst the ripe age to which they had attained and the family history elicited from them proved their right to rank among the best constitutions pissible.

CASE 4.-A miner seventy-five years of age had had a right inguinal hernia for more than five years. He had been, besides pursuing his mining work, a mason, a navry, and a brickmaker. His father (a farmer) died at forty years of age from the effects of a fall off his horse; he had always been a strong man. His mother died when between fifty and sixty years of age. She had never been laid up for a single day in her life.

CASE 5-A labourer seventy-four years of age had a right inguinal hernia of five years' and a left femoral hernia of eighteen months' standing; he had suffered from bronchitic asthma for more than six years. His father died at seventy years of age. His mother was more than eighty years of age.

CASE 6 -This patient was seventy-two years of age, with a double inguinal hernia of twenty-five years' standing; he contracted gonorrhoea when twenty-five years of age, with consequent stricture, besides numerous attacks of hæmorrhoids. He had done labourer's work for ten hours a day (from 6 A.M. to 6 P.M ) easily for many years. His father died at eighty-four years of age from natural decay. His mother died at sixty years of age from fever.

6. A man $6 \mathrm{ft}$. 2 in. in height, well set up and an athlete, came to show a commencing right inguinal hernia, which he easily controlled by wearing a truss. After discussing the question of its causation [for at first, with the usnal tendency to hunt for an accident, overstrain or unguarded act as a cause, he could give no reason why he, of all others, should be troubled in this way], he confessed that as a boy be had disliked going to the primitive construction which did duty for him in those days, and had for that rezson often gone as long as a week without a defæcation; that as he grew older he had suffered in consequence from intractable constipation with the usual straining at each effort, and that he had noticed, whilst straining, slight cracking sensations in the inguinal region; that these with the nneasy feeling they produced could always be arrested by lifting the right thigh so as to press it against the abdomen, and that now looking back he could easily understand that his old habits of procrastination of the fæcal act stood in the direct line of causation to his present hernia.

7. Whenever two or more herniæ occurred in one man, whilst an explanation was generally glibly forthcoming for the first, any inquiry into the history of the later ones was met by ignorance of any further cause. It appeared only natural that if the abdomen gave way at one point it should continue to do so at others.

8. Certain occupations which act in a similar way appear also to produce chronic hernia. Thus, one patient, a hawker, attributed his hernia, and, as I think, rightly, to the constant shouting required in his calling. Another case was a very interesting one. No reason whatever could be found in this man, who was at sixty-eight years of age a wellbuilt, sturdy-looking fellow, with a soldierly bearing and a perfectly healthy history, until I elicited the fact that he bad been in several regimental bands, where he had played on the bombardon, bassoon, tenor trombone, and the cornet. In the latest book on this subject by Macready ${ }^{11}$ lists are given of the occupations of the sufferers from bernia, and he remarks, contrary to the opinion of Kingdon, ${ }^{12}$ " that the proportion of ruptured persons in a trade fairly corresponds with the severity of the toil," but he notices that the gardener, the hawker, and the baker are very high on the list. "The gardener," he says, "takes a high place, because, perhaps, his position at the spade relaxes the structures of the groin at the moment of his most considerable effort. It has been noticed that the foresters in the Hartz Mountains

11 Macready on Ruptures, p. 51.

12 Holmes' System of Surgery, third edition, vol. ii., p. 749. suffered grievously from ruptures, and Stromeyer supposed that the stooping position, which they were obliged to adopt in cutting and binding wood, materially contributed to produce ruptures among them." As to this, one would naturally ask what particular strain is there in cutting and binding wood, and if there were, would not the very relaxation of the part be the best possible preventive of any dangerous result. He goes on to say : "It is difficult to explain why the hawker is so high upon the list, unless it is that he is not only ill-fed, but he is compelled to strain when shouting to call attention to his wares. The baker, also. is more frequently ruptured than might be anticipated. $\mathrm{He}$ has often to lift heavy weights, and is especially subject to the ill-effects of an atmosphere impure with gas, moisture and dust, whilst he is one who makes the night joint labourer with the day." Naturally, if one is imbued with the idea that undue strain combined with constitutional debility is the true cause of hernia, it becomes necessary to attempt to explain the relatively high position of bakers, gardeners, foresters, and hawkers, but if it be conceded that the efficient cause is what I suggest it becomes immediately most natural. Foresters, gardeners, and hawkers are all exposed to extremes of weather. Bronchitis, pneumonia, and asthma will be readily induced in them, whilst bakers live in a peculiarly irritating atmosphere, besides being at one time exposed to a high temperature and at another often to a very low one. If the list is examined with the former notion, it is still more difficult to explain why the gardener should rank higher than the blacksmith, or the cellarman than the mason; but viewed in the latter way each trade falls naturally into its position, from the gasworks service at the top to the clerk and tobacconist at the bottom.

In discussing the question of the constitution of herniated persons we are handicapped by the fact that there exists no definite standard to which we can appeal as proving that a man has a normal muscular condition or that his constitution cannot be considered to be debilitated; but some assistance may be obtained from certain statistics. The tables furnished by the 'Truss Society when compared with the Registrar General's report show that hernia apparently does not shorten life, inasmuch as, whilst 75.44 per cent. occur before forty years of age and 6779 per cent. before thirty-five years of age, deaths from hernia occur in the proportion of 93.15 per cent after thirty-five years of age, and at seventy-five years of age there are as many as at forty-five years of age, and at eightyfive years of age, and upwards, there are nearly as many as at twenty-five years of age. Here, again, the conclusions are falsified by the universal custom of grouping all hernix together as varieties of the same malady. Were chronic hernix quoted separately the contrast would be still more striking. I cannot help also emphasising the fact once more, which is clearly shown by the above figures, that so large a proportion of men with hernix live to a good old age, outliving their fellows, although burdened with this dis. ability, goes to prove that taken collectively they are rather men of better material than ordinary. Further to accentuate this, I have contrasted the deaths from hernia and those from scrofula. Of course, scrofula does not coincide with the relaxed muscular condition ascribed to herniated patients. but it is the nearest condition tabulated in the RegistrarGeneral's returns, and I instance it simply as exemplifying the fact that persons of a poor type of physique show a typical death-rate in absolute contrast to that of bernia. It will be seen that, putting all hernix on one side occurring before five years of age as almost certainly congenital, there is a progressive rise through small figures up to sixty-five years of age, whilst in scrofula there is an almost unbroken decrease from the commencement onwards. Compare, on the other hand, the deaths from hernia with those from bronchitis, emphysema, and asthma, and the types of each will be seen to be almost identical.

The next table gives confirmatory evidence. Men entering the army may be considered to be picked men, as any who show the presence of deformity or debility either at the time of enlistment or within three months after are rejected, and I understand that the standard required for cavalry men is distinctly higher than that for infantry. Yet by the reports of the Surgeon-General for the years 1868-71 inclusivethe latest I can obtain giving this particular informationcavalry and artillery show larger percentages of sufferers from hernia than infantry. If the Household troops are omitted, as I think they fairly may be, the percentage is still higher, being for cavalry and artillery, 3.05 ; for infantry, 178 . What is the explanation? I suggest that it is due to 
the multitudinous concussions to which the abdominal be rendered more probable; (5) that in the case of chronic cavities of artillerymen and cavalrymen are subjected-the hernia the cause is never one acting suddenly and singly, as tatter by the English military fashion of riding and the former by the bumping over uneven ground with their springless gun-carriages.

Without doubt in any attempt at radical cure of chronic hernia the choice of the operation best suited to the th overlifting, strains, falls, \&c., but always one acting slowly, persistently, gently, habitually (such causes are difficulties in urination and defæcation, certain occupations, and chiefly and most prominently coughing in all its forms); and (6) that the claims of any operation for the radical cure of chronic articular case is a matter of the ntmost importance; but hernia cannot at present be properly estimated, and that they

Table I. - Comparison between Dates of Deaths from Hernia ano from Scrofula.

Registrar-General's Report, 1891.

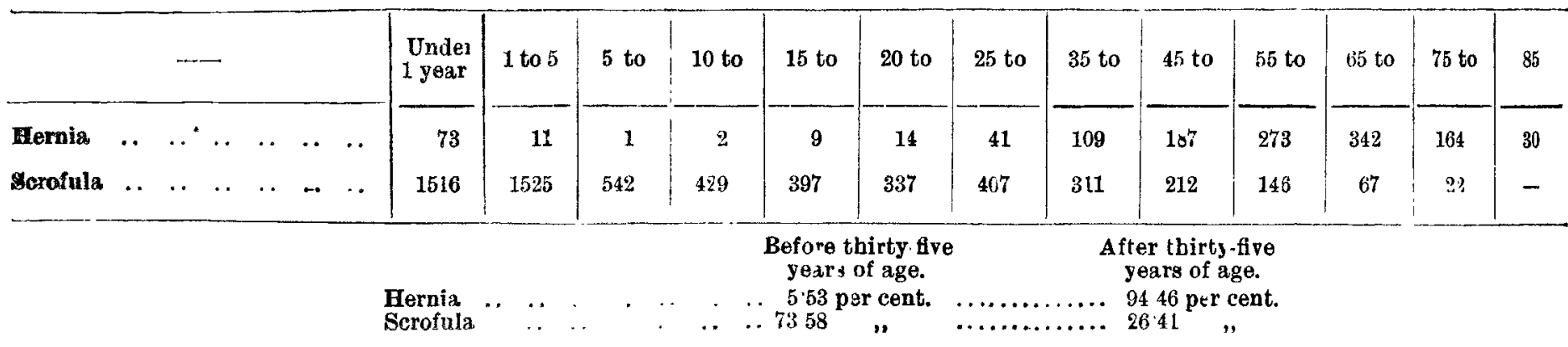

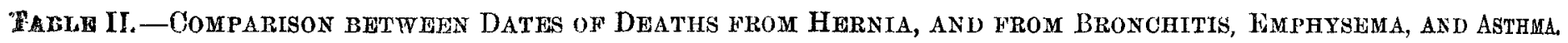
Registrar-General's Report, 1891.

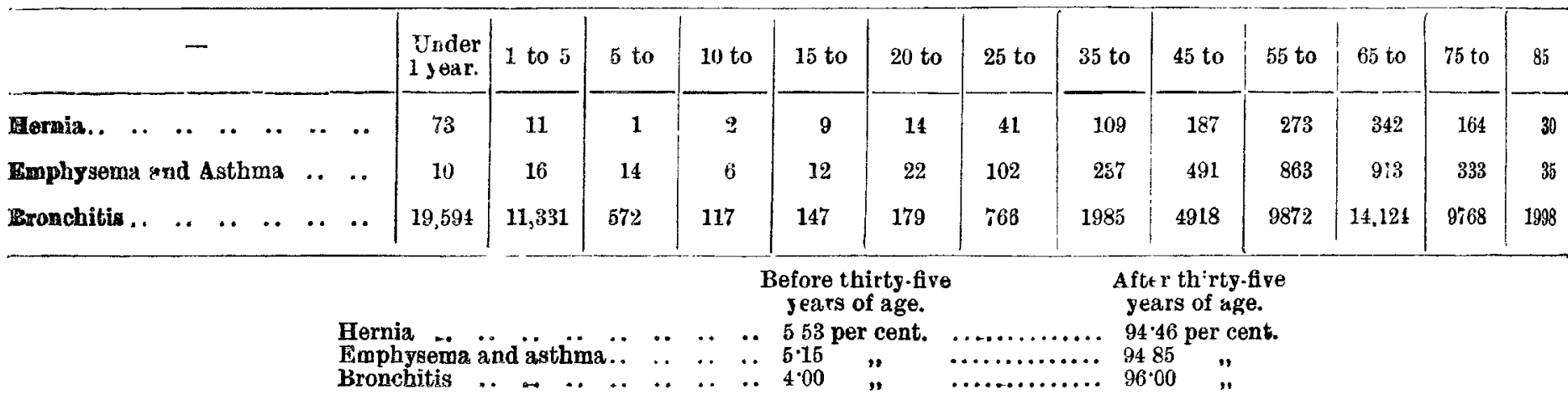

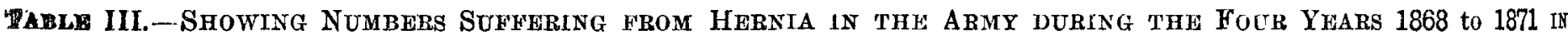
Each arm of the Service, with actual strengths and Percentage.

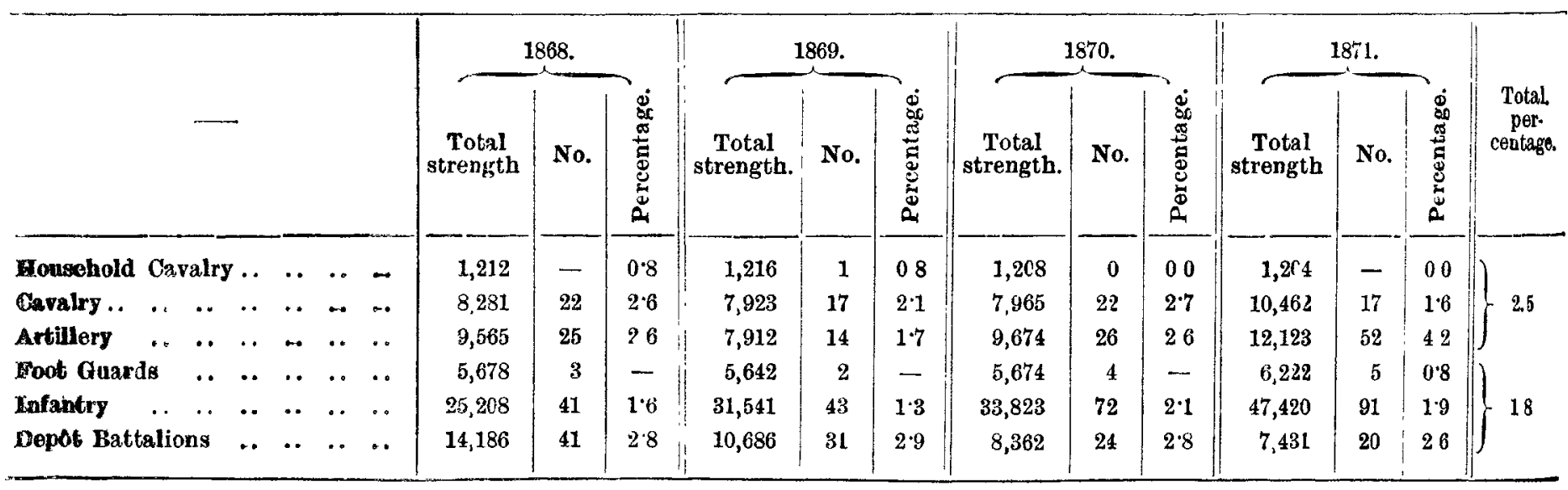

even the best planned operative measure may end in failure or relapse, which is much the same thing, if the cause which originally produced the rupture is still in action. To be certain of its previous removal it is obviously necessary above everything else that there should be no doubt as to its identity. To assist in determining this is the aim of this paper, and the conclusions which appear to me justifiable are : (1) that chronic and acute hernise are absolutely different hings, agreeing only in the fact that they are both protrusions of viscera through their normal environments; (2) that they differ in etiology, pathology, and course ; (3) that, especially from the point of view of radical cure, it is important to distinguish between them; (4) that in discussing the feasibility of operations for radical cure, and espeeially the permanency of their results, the etiology of chronic lernia is of immense importance, since an operation for the cure of the results of a cause is almost certain to be useless whilst the cause remains in operation, and if the cause can be found the patient may be warned to aroid it after the oneration bas been performed, in order that permanency may never can be unless acute and chronic herniæ are absolutely separated and the true effective causes of them are duly appreciated, these causes being previously carefully eliminated. St. Ann's-square, Manchester.

Workhouse Training for Nurses.-Dr. Robinson, of the Infirmary, Bancroft-road, N.E., informs us that the time of probation for their nurses is two years, not one. We are glad to make this correction.

Notringham Medico-Chirurgical Society.The annual dinner of this society was presided over by Dr. Walter Hunter at the Flying Horse Hotel on Thursday, Feb. 1st. In proposing the toast of the evening Dr. A.W. Hare said that the influence of medical societies could not be too highly estimated, in drawing medical men into closer relationship with one another, in : timulating thought, and in promoting the advancement of knowledge, both along practical and scientific lines. 
The LANCKT,] DR. RINGER AND DR. PHEAR : THE DIAGNOSIS OF CARDIAC MURMURS. [FeB. $10,1894.325$

\section{SOME PRACTICAL POINTS CONCERNING THE DIAGNOSIS OF CARDIAC MURMURS.}

BY SYDNEY RINGER, M.D. LOND., F.R.S.,

PIISICIAN AND PROFESSOR OF CLINICAL MEDICINE AT UNIVERSITY COLLEGE HOSPITAL;

$$
\text { AND }
$$

ARTHUR G. PHEAR, M.B. CANTAB, M.R.C.P. LOND.

THERE are many considerations of practical interest in connexion with the examination of the heart which deserve attention if fallacies are to be avoided and reliable diagnoses obtained. We desire here to notice two such matters-(1) the effect of exercising pressure with the stethoscope, and (2) the influence of slight change in posture. We have not been able to find any reference to either of these points in the various text-books on the subject.

\section{The Modification of Murmurs by Pressure.}

If, when listening to a murmur, pressure be made with the stethoscope the character of the murmur is altered. This modification is twofold - the murmur is weakened and its pitch is raised. With a few exceptions, to which reference will be made presently, we have found this effect of pressure to be universal. It may be brought about, however, as might be expected, more readily in some cases than in others thus in children with elastic and resilient chest walls slight pressure is sufficient to cause a well-marked modification; to produce the same degree of change in adults with more rigid chest walls a greater amount of pressure must be employed; while the effect is least marked in old people whose rib cartilages have become ossified and whose chest walls are extremely rigid and unyielding. The modification is more readily obtained in fat than in thin people. The slightest pressure is often sufficient to considerably modify the murmur ; even the weight of the stethoscope may cause a difference, so that in the pursuance of these investigations we have found it necessary to use a binaural in place of the wooden stethoscope, with which great pressure may be exercised nnwittingly; with the binaural stethoscope the pressure employed is under control and can be graduated. It is not necessary that the pressure should be applied over the point of greatest intensity of the murmur or over the point of production. Wherever the murmur can be heard the effect of pressure is the same ; indeed, it can often be more readily produced at a distance from the point of production than near to it. A case may be quoted of mitral regurgitation in a boy five years of age in whom a long, loud, systolic murmur was audible all over the chest, back, and front, the spot of maximum intensity being at the apex-beat. 'The murmur was heard very distinctly at the angle of the left scapula, but on exerting the slightest pressure at this point it became exceedingly faint; a moderate amount of pressure sufficed to obliterate it. In front the effect of pressure was evident more in modification of pitch than of intensity, gentle pressure causing a wellmarked rise of pitch. On increasing the pressure the murmur became rapidly weaker at the same time as the pitch was raised.

The same points may be illustrated by experiment. If water at high pressure be allowed to pass through indiarubber tubing, in the course of which a small constriction has been made by string or otherwise, a loud, continuous murmur is generated. If the tubing be laid on a piece of board the murmur is conducted along the board and may be heard on applying a stethoscope to the board at a distance from the tubing; if a thin piece of cotton wool be now placed between the stethoscope and the board, and the former be gradually pressed down firmly on to the latter, the murmur becomes weak and its pitch is raised-the same result as is obtained when auscultating a cardiac murmur. It will be noticed that in this experiment the production of the murmur is in no way interfered with, and the conclusion is inevitable that the modification is one of conduction, not of production; this throws some light on the point referred to above-namely, that in auscultation of the chest, no matter where the stethoscope be applied, provided only a murmur be audible, the effect of pressure is the same.

It is laid down in text-books, and generally accepted, that the intensity of a pulmonary hæmic murmur is increased by pressure. This is undoubtedly true in some instances, and in many children a murmur can be actually produced where none was audible before by properly applied pressure; we find, however, that in by far the larger number of hæmic murmurs pressure, as would be expected, has the same effect as in other murmurs-namely, the intensity of the murmur is not increased, but diminished, and the pitch of the murmur is raised. Soft hæmic murmurs are readily obliterated before any modification of pitch can be detected; with louder murmurs the earliest effect of pressure is usually to raise the pitch before any notable weakening occurs, a greater degree of pressure being required to weaken the murmur than to modify the pitch. We are inclined to think that this variation in the behaviour of hæmic murmurs to pressure depends on whether the actual production of the murmur is modified by the pressure or not; in those cases where the pulmonary artery can be actually pressed upon and dimpled doubtless an existing murmur will become more loud or a murmur will be produced where there was none before. In order to produce a murmur in a child it is necessary to use a stethoscope with a small chest-piece which can be fitted between the rib cartilages in the second left interspace, and firm pressure inwards and backwards must be exercised; it is clear that a murmur thus produced is the result of an actual flattening of the pulmonary artery by the pressure employed. In the majority of cases of hæmic murmur, however, where pressure weakens the murmur the production of the murmur cannot anyhow be supposed to be modified, since the change in character may be obtained equally well, or even more readily, at a distance from the point of production than immediately over this point; the modification, therefore, has to do solely with conduction.

Some comment is necessary on the subject of "pitch" in connexion with murmurs. The word is apt to be misleading, inasmuch as, strictly speaking, murmurs cannot be said to possess definite pitch except in rare cases of truly musical murmurs. A murmur should properly be regarded as an aggregation of noises affording a general impression of pitch so far that one murmur can be said to be of higher or lower pitch than another; but the pitch cannot be defined. On exercising pressure while listening to a murmur the impression afforded is that the lower-pitched noises which enter into the composition of the murmur are weakened or abolished, leaving the higher-pitched noises prominent. This produces the broad effect of rise in pitch. The high-pitched elements of a murmur bear no such relation to the low-pitched elements as harmonics to the ground note of a musical sound; a murmur, being a combination of noises, possesses no harmonics. In the uncommon cases of true musical murmur, to which definite pitch can be assigned, the pitch remains constant whatever the pressure be. Similarly if a vibrating tuning-fork be placed at one end of a board, and the other end be auscultated (a thin piece of cotton wool having been placed between the chest-piece of the stethoscope and the board), the note heard remains constant, its pitch being unaltered whether firm or light pressure be exercised with the stethoscope.

In differentiating between the various murmurs which may be produced at the cardiac orifices reliance is usually placed on these points: (1) the time of the murmur; (2) the position of maximum intensity; (3) the degree and direction of conduction and conrection (convection in the case of murmurs nearly always playing the more important part) ; and (4) other qualities, which may be included generally under pitch and timbre. The consideration of pitch, harshness, blowing character, and such qualities is held to be of less importance than the determination of the point of maximum intensity and the degree and direction of convection or conduction, and it is doubtless right to give to these latter the first place ; still, supposing a murmur to be heard at the base of the heart and a murmur also at the apex, and supposing the one to be a low-pitched, rough murmur and the other a high-pitched, blowing one, it would be most tempting to conclude that with characters so opposite the two murmurs must be distinct; and yet it will be found that the first murmur can be brought to assume all the characters of the second by the application of pressure -it will become soft, high-pitched, and blowing. We have found it frequently to be the case that without any variation in the degree of pressure employed the pitch of a murmur is different at different points of the chest; the alteration is usually in the direction of a rise in pitch as the stethoscope is carried away from the point of production of the murmur- 